\title{
Aortic mural thrombus visualised on transoesophageal echocardiography
}

\author{
Zhehao Dai, ${ }^{1}$ Terunobu Fukuda, ${ }^{1}$ Yasutoshi Shiratori, ${ }^{2}$ Nobuyuki Komiyama ${ }^{1}$
}

'Department of Cardiology, St. Luke's International Hospital, Tokyo, Japan

${ }^{2}$ Department of

Gastroenterology, St. Luke's International Hospital, Tokyo, Japan

\section{Correspondence to}

Dr Zhehao Dai, daizh@luke.ac.jp

Accepted 12 February 2019

\section{DESCRIPTION}

A 57-year-old man with hypertension, dyslipidaemia and type 2 diabetes was admitted to our hospital for severe acute pancreatitis. Despite management with adequate intravenous fluid and analgesic, he developed hypovolaemic shock within 12 hours after admission. He underwent contrast-enhanced CT for further investigation, which occasionally demonstrated a newly developed $28 \times 13 \mathrm{~mm}$ mural mass attached to the focally calcified lesser curvature of the aortic arch, which was consistent with a thrombus (figure 1A). Given the high risk of surgery and thrombolysis therapy with his condition, we immediately initiated anticoagulation with unfractionated heparin. Although the shape and size of the thrombus was unchanged, a newly developed asymptomatic splenic infarction was noted on repeat CT on the eighth day. To assess thrombus mobility for the prediction of further embolism and to formulate the treatment plan we performed transoesophageal echocardiography (TOE), which showed a pedunculated and hyperechoic minimally mobile thrombus indicating its organisation (figure 2, videos 1 and 2). We therefore continued anticoagulation with oral warfarin and discharged him on the 21 st day. His thrombus resolved in 2 months (figure 1B) and has not recurred in 5 months.

Aortic mural thrombus is an uncommon entity that has been reported to develop primarily or secondarily due to multiple underlying medical conditions

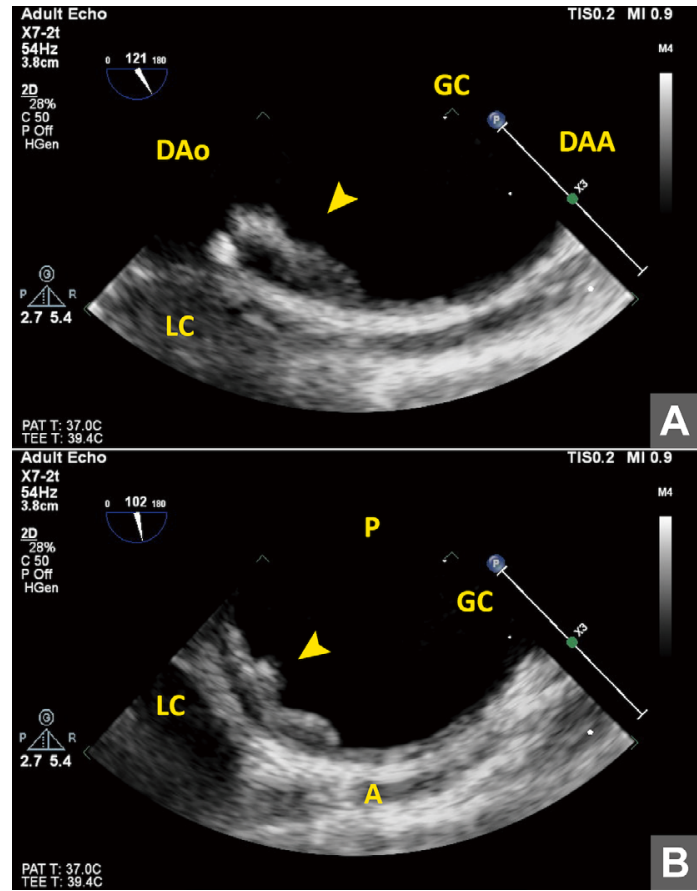

Figure 2 Transoesophageal echocardiography demonstrating organised hyperechoic mural thrombus (arrow head) with minimal mobility. (A) oblique view. (B) short-axis view. A, anterior; DAA, distal aortic arch; $D A o$, descending aorta; GC, greater curvature; LC, lesser curvature; $P$, posterior.
Check for updates

(C) BMJ Publishing Group Limited 2019. No commercial re-use. See rights and permissions. Published by BMJ.

To cite: Dai Z, Fukuda T, Shiratori Y, et al. BMJ Case Rep 2019;12:e229212. doi:10.1136/bcr-2019 229212
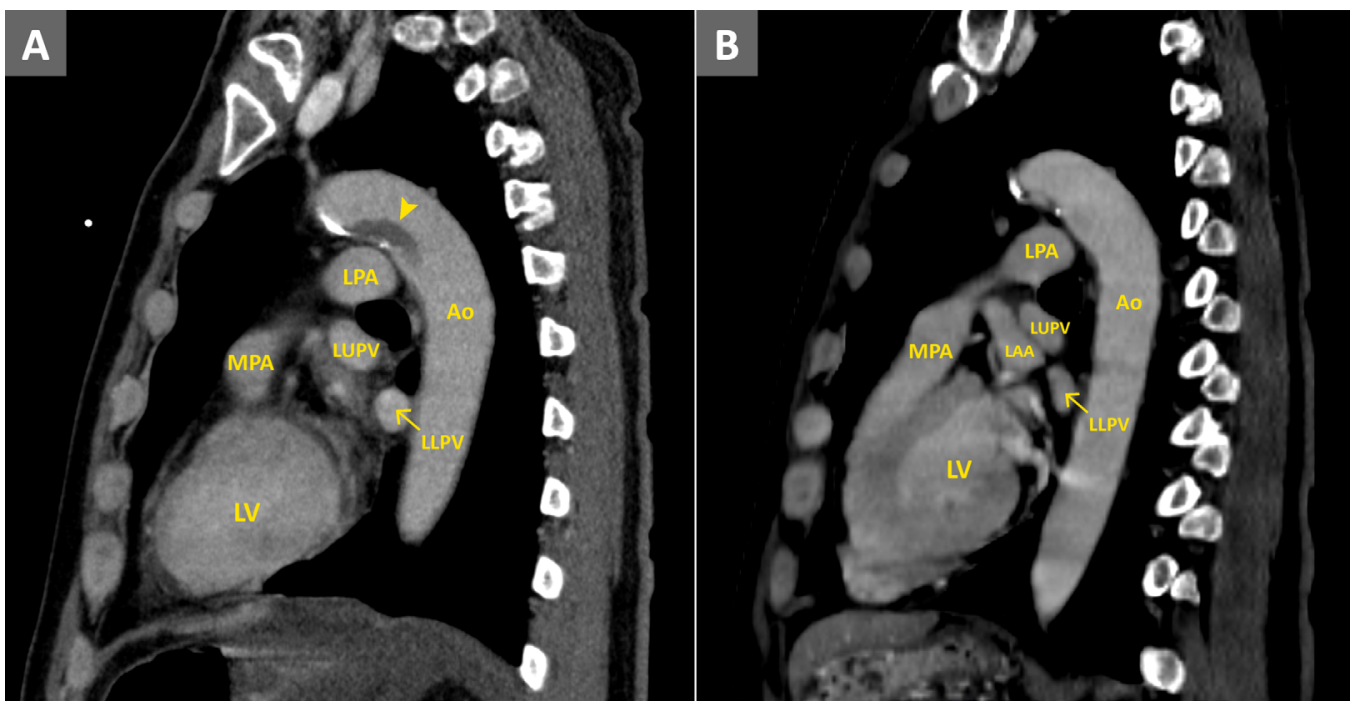

Figure 1 Contrast-enhanced CT revealing an aortic mural thrombus (arrow head) in the aortic arch on the day of admission (A), which resolved in 2 months (B). Ao, aorta; LAA, left atrial appendage; LLPV, left lower pulmonary vein; LPA, left pulmonary artery; LUPV, left upper pulmonary vein; LV, left ventricle; MPA, main pulmonary artery. 


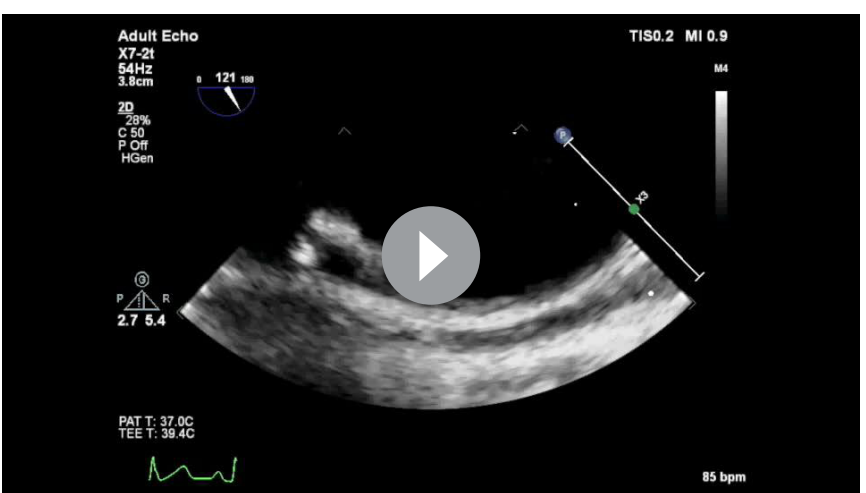

Video 1 Transoesophageal echocardiography (oblique view) demonstrated organised hyperechoic thrombus with minimal mobility.

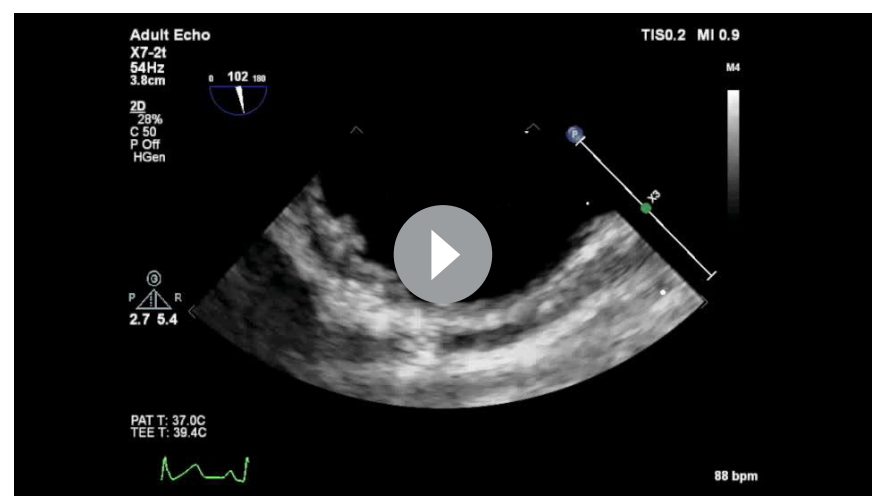

Video 2 Transoesophageal echocardiography (short-axis view) demonstrated organised hyperechoic thrombus with minimal mobility.

including acute pancreatitis as in the present case and administration of steroid therapy. ${ }^{12}$ Previous small-scale studies have indicated that conservative therapy, endovascular balloon thrombectomy, endovascular stent graft coverage or surgical removal could be a treatment option whereas no standardised consensus has been

\section{Learning points}

Aortic mural thrombus could develop primarily or secondarily due to various underlying diseases. No standardised consensus has been reached regarding its treatment.

- Transoesophageal echocardiography enables detailed assessment of thrombus mobility in a real-time manner, which substantially helps decide further treatment plan.

established due to the rarity and heterogeneity of this disease. ${ }^{1-4}$ When we discuss the treatment of aortic mural thrombus, evaluation of thrombus mobility is of fundamental importance in preventing embolic complications. In the present case, TOE strengthened the detailed assessment of thrombus mobility with its high spatial and temporal resolution in a real-time manner.

Contributors ZD planned and designed this report, collected and analysed data, and drafted the article. TF, YS, and NK interpreted data and critically revised the manuscript. All authors approved the submitted version of the manuscript.

Funding The authors have not declared a specific grant for this research from any funding agency in the public, commercial or not-for-profit sectors.

Competing interests None declared.

Patient consent for publication Obtained.

Provenance and peer review Not commissioned; externally peer reviewed.

\section{REFERENCES}

1 Weiss S, Bühlmann R, von Allmen RS, et al. Management of floating thrombus in the aortic arch. J Thorac Cardiovasc Surg 2016;152:810-7.

2 Chong BK, Yun JK, Kim JB, et al. Multiple ascending aortic mural thrombi and acute necrotizing mediastinitis secondary to acute pancreatitis. Korean J Thorac Cardiovasc Surg 2016:49:401-4.

3 Schneiderman J, Feinberg MS, Schwammenthal E, et al. Protruding aortic arch thrombus: treatment with minimally invasive surgical approach. J Vasc Surg 2004:40:1083-8.

4 Verma H, Meda N, Vora S, et al. Contemporary management of symptomatic primary aortic mural thrombus. J Vasc Surg 2014;60:1524-34.

Copyright 2019 BMJ Publishing Group. All rights reserved. For permission to reuse any of this content visit

https://www.bmj.com/company/products-services/rights-and-licensing/permissions/

BMJ Case Report Fellows may re-use this article for personal use and teaching without any further permission.

Become a Fellow of BMJ Case Reports today and you can:

- Submit as many cases as you like

- Enjoy fast sympathetic peer review and rapid publication of accepted articles

- Access all the published articles

- Re-use any of the published material for personal use and teaching without further permission

For information on Institutional Fellowships contact consortiasales@bmjgroup.com

Visit casereports.bmj.com for more articles like this and to become a Fellow 